\title{
Anxiety, depression and concerns of pregnant women during the COVID-19 pandemic
}

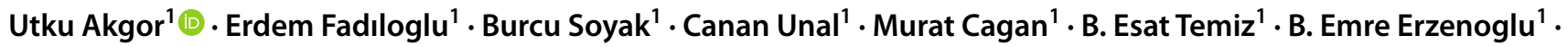 \\ Sertac $\mathrm{Ak}^{2,3} \cdot$ Murat Gultekin ${ }^{1}$. Ozgur Ozyuncu ${ }^{1}$
}

Received: 25 June 2020 / Accepted: 15 December 2020 / Published online: 12 January 2021

(c) The Author(s), under exclusive licence to Springer-Verlag GmbH, DE part of Springer Nature 2021

\begin{abstract}
Purpose In December 2019, the emerging of a novel coronavirus (COVID-19) has influenced the whole world. The current pandemic also triggers several psychological changes. Uncertainties and changes in health practices may cause anxiety, depression, and concerns on vulnerable populations such as pregnant. This study aims to survey the pregnant women to capture the psychological impact and perceptions during the pandemic.

Methods A total of 297 pregnant women aged $\geq 18$ years were enrolled in May 2020. We evaluated the hard-copy survey included questions about demographic and clinical information of patients, 95\% confidence intervals of a COVID-19-related questionnaire in a Likert scale and 14-item Hospital Anxiety and Depression Scale (HADS).

Results A total of 297 pregnant women were included in this study with a mean age of 27.64. Most patients (82.5\%) had concerns about infecting their babies during delivery. The fear of infection of the fetus during delivery revealed elderly age and having anxiety as the unique significant risk factors.

Mean HADS-A and HADS-D scores were $7.94( \pm 4.03)$ and $7.23( \pm 3.84)$, respectively. Multivariate analysis showed having anxiety was associated with a high HADS-D score and concern about the inability to reach obstetrician, and being in advanced age, having a high HADS-A score, and concern about the inability to reach obstetrician demonstrated significant effects on HADS-D score.

Conclusion We conclude that in future pandemics, communications and reassurance of the patients should be prioritized upon their routine ante-natal care to avoid increased levels of anxiety and even depression.
\end{abstract}

Keywords COVID-19 $\cdot$ Pandemic $\cdot$ Pregnancy $\cdot$ Psychological impact $\cdot$ Anxiety $\cdot$ Depression

\section{Introduction}

At the end of December 2019, the emerging of a novel coronavirus (COVID-19) has influenced the whole world. The current pandemic also triggers several psychological changes over the people with the main impact on anxiety and depression [1]. However, the situation may differ when compared among different patient populations and healthy

Utku Akgor

utkuakgor@gmail.com

1 Department of Obstetrics and Gynecology, Faculty of Medicine, Hacettepe University, 06230 Ankara, Turkey

2 Stress Assesment and Research Center (STAR), Hacettepe University, Ankara, Turkey

3 Faculty of Medicine, Department of Psychiatry, Hacettepe University, Ankara, Turkey individuals due to the unknowns of the pandemic. On the other hand, the health care systems were threatened with risk of collapsing during the pandemic. Patients were categorized and prioritized for immediate or delayed access to hospitals. These measures increased the anxiety of the patients in addition to already exisiting concerns about the COVID.

Several patient groups were found to be more vulnerable to COVID infection during the pandemics such as cancer patients or pregnant women. COVID-19 was speculated to be posing a higher risk to this vulnerable group due to the suppressed immune system during pregnancy. Although various possible complications of pregnancy are mentioned, COVID-19 maternal and fetal effects have not been fully elucidated [2]. These uncertainties and changes in health practices may cause additional anxiety and depression on pregnant women. Additionally, changes in the capacity of health care facilities that may result in a possible collapse in 
health care system and changing health care policies may be creating further anxiety on the pregnant women.

In this article, it is aimed to determine the level of anxiety and depression and perspectives of pregnant women during the pandemic. To our knowledge, there are only a few analysis in the literature evaluating these aspects from the pregnants's perspectives [3]. This study is one of the unique prospectively designed study with a validated anxiety and depression scores from a large COVID center in Turkey.

\section{Methods}

\section{Participants and design}

The participants of current prospective study included aged above 18 years pregnant women that attended Hacettepe University, Obstetric and Gynecology Department in May, 2020. The pregnant women with a history of any psychiatric disorder and the gestation weeks under six were excluded from the study. A total of 1225 pregnant women that meet the criteria were approached to participate in current study, among which 321 had agreed (321/1225, 25.5\%). However, 24 of 321 patients had more than 2 missing values in the survey and those were also excluded from the study. This study was approved by the Ethics Committee of Hacettepe University, Ankara (approval number: GO 20/541).

\section{Survey}

The survey consisted of three parts: Part A included questions about demographic and clinical information of the participants, Part B included several questions in a Likert scale and has evaluated the effects of COVID-19 pandemic on pregnant women together with attitudes and experiences of pregnants during the pandemic. Finally, Part $\mathrm{C}$ was composed of validated and translated version of a 14- item Hospital Anxiety and Depression Scale (HADS) [4]. The validity and reliability of this survey was previously established in a Turkish population by Aydemir [5]. HADS has two subscales evaluating anxiety (HADS-A) and depression (HADS-D). Each question in this Likert-type scale scored from 0 to 3 . Each survey has a maximum score of 21. The scores ranging $0-8$ indicate healthy patients, $8-<11$ represent borderline for depression or anxiety, and $\geq 11$ show severe depression or anxiety.

\section{Statistical analysis}

Student's $t$ test, and chi-square test were used for the univariate comparisons of the groups. Binary regression analysis was performed to evaluate the independent association of variables with 'afraid of infecting my baby during delivery' and HADS scores. For variables in the equation Odds ratios and lower and upper levels of $95 \%$ of confidence intervals were calculated. The cut-off for statistical significance was set at a $p$ value of $<0.05$. All data were entered into and analyzed by the Statistical Package for the Social Sciences, Windows Version 23.0 (SPSS, Chicago, IL, USA).

\section{Results}

A total of 297 pregnant women were included in this study with a mean age of $27.64( \pm 5.27)$. Two hundred sixtythree $(n=263 ; 88.6 \%)$ pregnant women were younger than 35 years and $34(11.4 \%)$ were at 35 years or older. The mean gestational week was $27.04( \pm 8.85)$. Thirty-two $(n=32$; $10.8 \%)$ patients were at the first trimester, $117(39.4 \%)$ were at the second and the remaining $148(49.8 \%)$ were at the third trimester. Of 297 patients, 131 (44.1\%) were nulliparous and 37 (12.5\%) had comorbid diseases. Mean HADS-A and HADS-D Scores were $7.94( \pm 4.03)$ and $7.23( \pm 3.84)$, respectively (Table 1).

One hundred seventy-nine $(n=179 ; 60.3 \%)$ of pregnant women thought COVID infection risk was higher in their babies compared to themselves, and $82.5 \%(n=245)$ of these pregnant women had concerns about transmitting the infection to their babies during delivery if they are infected with COVID-19. A great majority had believed that pregnant women have a higher risk for COVID infection than nonpregnant population $(n=209 ; 70.4 \%)$. Most patients $(79.5 \%$, $n=236$ ) were afraid of getting COVID infection from the hospital during their follow-up or birth. About half of the pregnant women $(51.5 \%, n=153)$ were concerned about not being able to reach to their doctors during the COVID

Table 1 Clinical and demographic variables of patients

\begin{tabular}{lc}
\hline Variables & $n(\%), N=297$ \\
\hline Age & \\
$<35$ & $263(88.6)$ \\
$\geq 35$ & $34(11.4)$ \\
Trimesters of pregnancy & \\
1 & $32(10.8)$ \\
2 & $117(39.4)$ \\
3 & $148(49.8)$ \\
Parity & \\
Nulliparity & $131(44.1)$ \\
Multiparity & $166(55.9)$ \\
Comorbidity & \\
Yes & $37(12.5)$ \\
No & $260(87.5)$ \\
HADS-A (mean) & $7.94( \pm 4.03)$ \\
HADS-D (mean) & $7.23( \pm 3.84)$ \\
\hline
\end{tabular}


epidemic. More than half of pregnant $(66 \%, n=196)$ were also concerned about experiencing pregnancy complications if their follow-ups were postponed / cancelled (Table 2).

A subgroup analysis with multivariate regression analysis evaluating the fear of infection of the fetus during delivery revealed elderly age ( $>35$ years old) and having anxiety (HADS score above 8) as the unique significant risk factors. Other parameters such as having comorbidities, nulliparity, gestational age, and depression (HADS score above 8) were not significant factors effecting the fear of intra-uterine or neo-natal infection risk of the babies. (Table 3).

Similiarly, a multivariate binary regression analysis was conducted to investigate the factors for elevated HADS-Anxiety (A) and HADS-Depression (D) scores. Variables that independently influenced the HADS-A score were HADS-D score (OR 5.41; 95\% CI 2.81-10.40; $p=0.001$ ), and being concerned about not reaching the obstetrician for follow-ups during the COVID-19 pandemic score (OR 1.42; 95\% CI $1.18-3.16 ; p=0.04)$. The other variables did not have any significant effect on HADS-A score (Table 4).

Age (OR 1.41; 95\% CI 0.33-2.87; $p=0.02$ ), HADS-A score (OR 5.38; 95\% CI 2.80-10.34; $p=0.001$ ), and concerns about not reaching the obstetrician for follow-ups during the COVID-19 pandemic (OR 2.61; 95\% CI 1.57-4.33; $p=0.001)$ demonstrated significant effects on depression according to HADS-D score (Table 5).

\section{Discussion}

To our knowledge, there are only a few analysis in the published literature evaluating these aspects from the pregnants's perspectives. Though the increased risk of psychiatric disorders is not directly associated with pregnancy; health problems in pregnants, unfavorable prenatal care,
Table 3 Risk factors for believing "I am afraid of infecting my baby during delivery"

\begin{tabular}{|c|c|c|c|c|}
\hline \multirow[t]{2}{*}{ Variables } & \multirow[t]{2}{*}{ Odds ratio } & \multicolumn{2}{|c|}{$\begin{array}{l}95 \% \text { Confidence } \\
\text { interval }\end{array}$} & \multirow[t]{2}{*}{$p$ value } \\
\hline & & Lower & Upper & \\
\hline $\begin{array}{l}\text { Age } \\
(\geq 35 \text { vs. }<35 \text { years })\end{array}$ & 1.90 & 3.89 & 6.81 & 0.04 \\
\hline $\begin{array}{l}\text { Comorbidities } \\
\text { (yes vs. no) }\end{array}$ & 0.97 & 0.68 & 1.39 & 0.89 \\
\hline $\begin{array}{l}\text { Nulliparity } \\
\text { (yes vs. no) }\end{array}$ & 1.12 & 0.60 & 2.08 & 0.60 \\
\hline $\begin{array}{l}\text { Gestational age } \\
\text { (trimester } 1 \text { vs. } 2 \text { vs. } 3 \text { ) }\end{array}$ & 1.20 & 0.76 & 1.89 & 0.42 \\
\hline $\begin{array}{l}\text { HADS-D score } \\
(\geq 11 \text { vs. }<11)\end{array}$ & 0.85 & 0.37 & 1.93 & 0.37 \\
\hline $\begin{array}{l}\text { HADS-A score } \\
(\geq 11 \text { vs. }<11)\end{array}$ & 2.25 & 1.95 & 5.25 & 0.01 \\
\hline
\end{tabular}

stressful life events, and complicated pregnancies were associated with the increased risk of mental disorders during pregnancy [6]. Currently, there are many observational studies on the psychiatric effects of the COVID-19 outbreak in the general population, healthcare workers, and vulnerable populations [7-9]. Few studies evaluating the psychiatric effects of SARS pandemic and COVID-19 on pregnant women have shown that this vulnerable population will face psychiatric challenges due to uncertainties, social isolation, severity of the disease, disinformation and increased risk of possible pregnancy complications [10, 11]. Concern and stress in pregnancy are associated with side effects such as preeclampsia, depression, increased nausea and vomiting during pregnancy, preterm labor, low birth weight, and low APGAR score [12-16].

Table 2 Concerns of pregnant women due to COVID- 19 pandemic

\begin{tabular}{|c|c|c|c|}
\hline \multirow[t]{2}{*}{ Questions } & \multicolumn{3}{|l|}{ Answers } \\
\hline & $\begin{array}{l}\text { Strongly } \\
\text { disagree or } \\
\text { disagree } \\
n(\%)\end{array}$ & $\begin{array}{l}\text { Neither agree } \\
\text { nor disagree } \\
n(\%)\end{array}$ & $\begin{array}{l}\text { Strongly } \\
\text { agree or } \\
\text { agree } \\
n(\%)\end{array}$ \\
\hline I think myself is more at risk than my baby because of the COVID infection & $64(21.5)$ & $67(22.6)$ & $166(55.9)$ \\
\hline I think my baby is at higher risk than myself because of COVID infection & $51(17.2)$ & $97(22.6)$ & $179(60.3)$ \\
\hline I think that pregnant women have a higher risk for COVID infection than other people & $44(14.8)$ & $44(14.8)$ & $209(70.4)$ \\
\hline I am afraid of infecting my baby during delivery if I get a COVID infection & $29(9.8)$ & $23(7.7)$ & $245(82.5)$ \\
\hline $\begin{array}{l}\text { I am afraid of getting COVID infection from the hospital environment during my follow-up or } \\
\text { birth }\end{array}$ & $31(10.4)$ & $30(10.1)$ & $236(79.5)$ \\
\hline $\begin{array}{l}\text { I am concerned about not meeting my doctor who followed my pregnancy during the COVID } \\
\text { epidemic }\end{array}$ & $90(30.3)$ & $54(18.2)$ & $153(51.5)$ \\
\hline $\begin{array}{l}\text { I am concerned about experiencing pregnancy complications if my follow-ups are postponed / } \\
\text { cancelled }\end{array}$ & $60(20.2)$ & $41(13.8)$ & $196(66)$ \\
\hline
\end{tabular}


Table 4 Risk factors for anxiety according to HADS-A score

\begin{tabular}{|c|c|c|c|c|}
\hline \multirow[t]{2}{*}{ Variables } & \multirow[t]{2}{*}{ Odds ratio } & \multicolumn{2}{|c|}{$\begin{array}{l}95 \% \text { Confidence } \\
\text { interval }\end{array}$} & \multirow[t]{2}{*}{$p$ value } \\
\hline & & Lower & Upper & \\
\hline $\begin{array}{l}\text { Age } \\
(\geq 35 \text { vs. }<35 \text { years })\end{array}$ & 0.45 & 0.16 & 1.27 & 0.13 \\
\hline $\begin{array}{l}\text { Comorbidities } \\
\text { (yes vs. no) }\end{array}$ & 0.77 & 0.35 & 1.77 & 0.36 \\
\hline $\begin{array}{l}\text { Nulliparity } \\
\text { (yes vs. no) }\end{array}$ & 0.70 & 0.40 & 1.22 & 0.21 \\
\hline $\begin{array}{l}\text { Gestational age } \\
\text { (trimester } 1 \text { vs. } 2 \text { vs. } 3 \text { ) }\end{array}$ & 0.87 & 0.64 & 1.41 & 0.77 \\
\hline $\begin{array}{l}\text { HADS-D score } \\
(\geq 11 \text { vs. }<11)\end{array}$ & 5.41 & 2.81 & 10.40 & 0.001 \\
\hline $\begin{array}{l}\text { Concerned about reaching the obstetrician for follow-ups dur- } \\
\text { ing the COVID-19 pandemic } \\
\text { (yes vs. no) }\end{array}$ & 1.42 & 1.18 & 3.16 & 0.04 \\
\hline $\begin{array}{l}\text { Concerned about infecting during the follow-up or delivery } \\
\text { (yes vs. no) }\end{array}$ & 1.35 & 0.70 & 2.57 & 0.36 \\
\hline
\end{tabular}

\begin{tabular}{|c|c|c|c|c|}
\hline \multirow[t]{2}{*}{ Variables } & \multirow[t]{2}{*}{ Odds ratio } & \multicolumn{2}{|c|}{$\begin{array}{l}95 \% \text { Confidence } \\
\text { interval }\end{array}$} & \multirow[t]{2}{*}{$p$ value } \\
\hline & & Lower & Upper & \\
\hline $\begin{array}{l}\text { Age } \\
(\geq 35 \text { vs. }<35 \text { years })\end{array}$ & 1.43 & 1.33 & 2.87 & 0.02 \\
\hline $\begin{array}{l}\text { Comorbidities } \\
\text { (yes vs. no) }\end{array}$ & 1.03 & 0.72 & 1.47 & 0.86 \\
\hline $\begin{array}{l}\text { Nulliparity } \\
\text { (yes vs. no) }\end{array}$ & 0.93 & 0.48 & 1.81 & 0.85 \\
\hline $\begin{array}{l}\text { Gestational age } \\
\text { (trimester } 1 \text { vs. } 2 \text { vs. } 3 \text { ) }\end{array}$ & 1.07 & 0.66 & 1.74 & 0.76 \\
\hline $\begin{array}{l}\text { HADS anxiety score } \\
(\geq 11 \text { vs. }<11)\end{array}$ & 5.38 & 2.80 & 10.34 & 0.001 \\
\hline $\begin{array}{l}\text { Concerned about reaching the obstetrician for follow-ups dur- } \\
\text { ing the COVID-19 pandemic } \\
\text { (yes vs. no) }\end{array}$ & 2.61 & 1.57 & 4.33 & 0.001 \\
\hline $\begin{array}{l}\text { Concerned about infecting during the follow-up or delivery } \\
\text { (yes vs. no) }\end{array}$ & 0.61 & 0.30 & 1.22 & 0.16 \\
\hline
\end{tabular}

Table 5 Risk factors for depression according to HADS-D score
Pregnant women participating in present study stated that the risk of COVID transmission in pregnant women may be higher than the general population. When we generalize pregnancy as an immunosuppressive condition, and according to current data, the susceptibility of pregnant women to respiratory pathogens and the development of severe pneumonia makes pregnant women more susceptible to COVID19 infection than the general population [17]. Beside these justified concern, another thought of many participants is that the infants had higher risks than pregnant women [18]. According to a review including 538 pregnant COVID-19 patients shows the vertical transmission of the novel coronovirus has not yet been proven, but the rate of preterm births and cesarian sections were increased [19]. Additionally, pregnant women are not reported to be under higher risk for mortality secondary to COVID-19 infection. Because of the conflict between literature knowledge and pregnant women's concerns, we may hypothesize that proper education of the patients by physicians may relief that anxiety in these aspects. However, there is evidence for higher depression scores among pregnant women with longer years of education which creates a dilemma [20].

Another source of concern is not being able to reach the doctor during follow-ups and postponing the appointment. Despite the fact that no pregnant woman's appointment was postponed and uninterrupted healthcare was provided during the outbreak in our department, more than half of the participants have concerns about delaying their appointment and not being able to reach their own specialists. We anticipated that the reason for these unnecessary concerns may be due 
to the possibility of a collapse in the healthcare system and all kinds of information pollution including media related to the outbreak.

The major concerns of the participants were hospitalacquired COVID-19 transmissions during follow-up and childbirth. The thought that is at the center of the concerns and disturbs almost all of the participants was 'I am afraid of infecting my baby during childbirth'. A study predicted that approximately $20 \%$ of infections in patients, and almost $90 \%$ of infections in medical staffs were due to hospital-acquired transmissions [21]. Although this concern has a scientific basis, our study showed that advanced maternal age and high anxiety score were the trigger for this condition. It is well known that advanced maternal age is strictly related with many of the obstetric complications, and this may be the rationale behind the higher anxiety for the patients with advanced maternal age.

Compromising the quality of care caused by not reaching the physician may result with negative pregnancy outcomes. This thought is one of the major elevated anxiety and depression causes in the present study. In contrast to some previous studies, we realized that patients are more concerned due to the inability to visit their doctors, rather than having being infected by COVID at the hospital visits [22]. In the pandemic process, where both being in the hospital and not being able to come to the hospital cause concerns, we found strong correlations between depression and anxiety. According to psychodynamics, depression is a general inhibition state and undermine actions, however anxiety is a general state of alertness and motivates people toward to actions. The presence of a factor that affects the whole world, such as COVID pandemic, can explain the positive correlation between these two different and almost opposite feelings.

The relationship between advanced maternal age and depression is controversial, but analysis showed that advanced maternal age, especially over 35 had higher levels of depression than other younger adult pregnant women [23, 24]. Our finding is consistent with those of prior studies. The increase of this risk has been attributed to several factors such as increased risk of obstetric complications [25], challenges in adapting to motherhood [23], and decreasing support from the social environment with advancing age [26]. The experience of childbearing at advanced maternal age did not appear to be the only cause of higher depression rates. In addition, the possibility of participants with advanced maternal age to report depression symptoms more effectively should not be forgotten, and there is a perception that young people are less affected by COVID infection in almost all of the society. However, some studies reported vice versa and concluded that younger pregnant women were more prone to depression during the COVID pandemic [22]. Altough many studies have revealed that patients having comorbidities during COVID infection are associated with worse clinical outcomes [27, 28]. Interestingly, in our study, it was observed that anxiety and depression scores of pregnant women with additional diseases were not high. The fact that there is heterogeneity in the comorbidity setup in our study and that subgroup analysis was not performed according to the severity of these comorbidities may be related to this result.

Increasing awareness about the transmission of the disease, explaining the precautions that can be taken for prenatal, postpartum, breastfeeding, and neonatal care; and also asking patients for psychiatry consultation are important in increasing the psychiatric well-being of pregnant women.

The prospective design of the study, use of a validated translated version of anxiety, and depression scores are the main powers of the study. In addition, the study reflects a single-center experience of one of the largest hospitals in Turkey which were also one of the largest designated COVID centers of the country. The center is not a private office or hospital and has the capacity to reflect the real pregnant population of the country compared to some other reports. Given these, we conclude that in future pandemics, communications and reassurance of the patients should be prioritized upon their routine ante-natal care to avoid increased levels of anxiety and even depression.

Author contributions UA: project development, manuscript writing, EF: manuscript writing/editing, BS: data collection or management, CU: data analysis, MC: protocol/project development, BET: data collection, BEE: data collection SAK: data analysis, MG: project development, OO: protocol/project development.

Funding No financial support was received for this work.

\section{Compliance with ethical standards}

Conflict of interest The authors declare that they have no confict of interest.

Ethical approval This study was approved by the Ethics Committee of Hacettepe University, Ankara (approval number: GO 20/541).

Informed consent Informed consent was obtained from all individual participants included in the study.

\section{References}

1. Rogers JP, Chesney E, Oliver D, Pollak TA, McGuire P, FusarPoli P, Zandi MS, Lewis G, David AS (2020) Psychiatric and neuropsychiatric presentations associated with severe coronavirus infections: a systematic review and meta-analysis with comparison to the COVID-19 pandemic. Lancet Psychiatry. https://doi. org/10.1016/S2215-0366(20)30203-0

2. Dashraath P, Wong JLJ, Lim MXK, Lim LM, Li S, Biswas A, Choolani M, Mattar C, Su LL (2020) Coronavirus disease 2019 
(COVID-19) pandemic and pregnancy. Am J Obstet Gynecol 222(6):521-531. https://doi.org/10.1016/j.ajog.2020.03.021

3. Rejnö G, Lundholm C, Öberg S, Lichtenstein P, Larsson H, D’Onofrio B, Larsson K, Saltvedt S, Brew BK, Almqvist C (2019) Maternal anxiety, depression and asthma and adverse pregnancy outcomes-a population based study. Sci Rep 9(1):13101. https ://doi.org/10.1038/s41598-019-49508-z

4. Zigmond AS, Snaith RP (1983) The hospital anxiety and depression scale. Acta Psychiatr Scand 67(6):361-370. https://doi. org/10.1111/j.1600-0447.1983.tb09716.x

5. Aydemir O (1997) Validity and reliability of Turkish version of hospital anxiety and depression scale. Turk J Psychiatry 8:280-287

6. Vesga-López O, Blanco C, Keyes K, Olfson M, Grant BF, Hasin DS (2008) Psychiatric disorders in pregnant and postpartum women in the United States. Arch Gen Psychiatry 65(7):805-815. https://doi.org/10.1001/archpsyc.65.7.805

7. Chen Q, Liang M, Li Y, Guo J, Fei D, Wang L, He L, Sheng C, Cai Y, Li X, Wang J, Zhang Z (2020) Mental health care for medical staff in China during the COVID-19 outbreak. Lancet Psychiatry 7(4):e15-e16. https://doi.org/10.1016/s2215-0366(20)30078-x

8. Tsai J, Wilson M (2020) COVID-19: a potential public health problem for homeless populations. Lancet Public Health 5(4):e186-e187. https://doi.org/10.1016/s2468-2667(20)30053-0

9. Wang C, Pan R, Wan X, Tan Y, Xu L, Ho CS, Ho RC (2020) Immediate Psychological Responses and Associated Factors during the Initial Stage of the 2019 Coronavirus Disease (COVID-19) Epidemic among the General Population in China. Int J Environ Res Public Health. https://doi.org/10.3390/ijerph17051729

10. Rashidi Fakari F, Simbar M (2020) Coronavirus pandemic and worries during pregnancy; a letter to editor. Arch Acad Emerg Med 8(1):e21-e21

11. Lee DTS, Sahota D, Leung TN, Yip ASK, Lee FFY, Chung TKH (2006) Psychological responses of pregnant women to an infectious outbreak: a case-control study of the 2003 SARS outbreak in Hong Kong. J Psychosom Res 61(5):707-713. https://doi. org/10.1016/j.jpsychores.2006.08.005

12. Qiao Y, Wang J, Li J, Wang J (2012) Effects of depressive and anxiety symptoms during pregnancy on pregnant, obstetric and neonatal outcomes: a follow-up study. J Obstet Gynaecol 32(3):237-240. https://doi.org/10.3109/01443615.2011.647736

13. Field T, Diego M, Hernandez-Reif M, Figueiredo B, Deeds O, Ascencio A, Schanberg S, Kuhn C (2010) Comorbid depression and anxiety effects on pregnancy and neonatal outcome. Infant Behav Dev 33(1):23-29. https://doi.org/10.1016/j.infbe h.2009.10.004

14. Rubinchik SM, Kablinger AS, Gardner JS (2005) Medications for panic disorder and generalized anxiety disorder during pregnancy. Prim Care Companion J Clin Psychiatry 7(3):100-105. https://doi. org/10.4088/pcc.v07n0304

15. Alder J, Fink N, Bitzer J, Hösli I, Holzgreve W (2007) Depression and anxiety during pregnancy: a risk factor for obstetric, fetal and neonatal outcome? A critical review of the literature. J Matern Fetal Neonatal Med 20(3):189-209. https://doi.org/10.1080/14767 050701209560

16. Littleton HL, Breitkopf CR, Berenson AB (2007) Correlates of anxiety symptoms during pregnancy and association with perinatal outcomes: a meta-analysis. Am J Obstet Gynecol 196(5):424432. https://doi.org/10.1016/j.ajog.2007.03.042

17. Liu H, Wang L-L, Zhao S-J, Kwak-Kim J, Mor G, Liao A-H (2020) Why are pregnant women susceptible to COVID-19?
An immunological viewpoint. J Reprod Immunol 139:103122103122. https://doi.org/10.1016/j.jri.2020.103122

18. Wong SF, Chow KM, Leung TN, Ng WF, Ng TK, Shek CC, Ng PC, Lam PW, Ho LC, To WW, Lai ST, Yan WW, Tan PY (2004) Pregnancy and perinatal outcomes of women with severe acute respiratory syndrome. Am J Obstet Gynecol 191(1):292-297. https://doi.org/10.1016/j.ajog.2003.11.019

19. Huntley BJF, Huntley ES, Di Mascio D, Chen T, Berghella V, Chauhan SP (2020) Rates of maternal and perinatal mortality and vertical transmission in pregnancies complicated by severe acute respiratory syndrome coronavirus 2 (SARS-Co-V-2) infection: a systematic review. Obstet Gynecol. https://doi.org/10.1097/ aog.0000000000004010

20. Durankuş F, Aksu E (2020) Effects of the COVID-19 pandemic on anxiety and depressive symptoms in pregnant women: a preliminary study. J Matern-Fetal Neonatal Med. https://doi. org/10.1080/14767058.2020.1763946

21. Evans S, Agnew E, Vynnycky E, Robotham JV (2020) The impact of testing and infection prevention and control strategies on within-hospital transmission dynamics of COVID-19 in English hospitals. medRxiv. https://doi.org/10.1101/2020.05.12.20095562

22. Wu Y, Zhang C, Liu H, Duan C, Li C, Fan J, Li H, Chen L, Xu H, Li X, Guo Y, Wang Y, Li X, Li J, Zhang T, You Y, Li H, Yang S, Tao X, Xu Y, Lao H, Wen M, Zhou Y, Wang J, Chen Y, Meng D, Zhai J, Ye Y, Zhong Q, Yang X, Zhang D, Zhang J, Wu X, Chen W, Dennis C-L, Huang H (2020) Perinatal depressive and anxiety symptoms of pregnant women along with COVID-19 outbreak in China. Am J Obstet Gynecol. https://doi.org/10.1016/j. ajog.2020.05.009

23. Muraca GM, Joseph KS (2014) The association between maternal age and depression. Journal of obstetrics and gynaecology Canada Journal d'obstetrique et gynecologie du Canada 36(9):803-810. https://doi.org/10.1016/s1701-2163(15)30482-5

24. Spence NJ (2008) The long-term consequences of childbearing: physical and psychological well-being of mothers in later life. Res Aging 30(6):722-751. https://doi.org/10.1177/016402750832257 5

25. Giri A, Srivastav VR, Suwal A, Tuladhar AS (2013) Advanced maternal age and obstetric outcome. Nepal Med Coll J 15(2):87-90

26. Carlson DL (1982) (2011) Explaining the curvilinear relationship between age at first birth and depression among women. Soc Sci Med 72(4):494-503. https://doi.org/10.1016/j.socsc imed.2010.12.001

27. Huang C, Wang Y, Li X, Ren L, Zhao J, Hu Y, Zhang L, Fan G, Xu J, Gu X, Cheng Z, Yu T, Xia J, Wei Y, Wu W, Xie X, Yin W, Li H, Liu M, Xiao Y, Gao H, Guo L, Xie J, Wang G, Jiang R, Gao Z, Jin Q, Wang J, Cao B (2020) Clinical features of patients infected with 2019 novel coronavirus in Wuhan, China. Lancet (London, England) 395(10223):497-506. https://doi.org/10.1016/ s0140-6736(20)30183-5

28. Wu Y, Zhang C, Liu H et al (2020) Perinatal depressive and anxiety symptoms of pregnant women during the coronavirus disease 2019 outbreak in China. Am J Obstet Gynecol 223:240.e1-40.e9

Publisher's Note Springer Nature remains neutral with regard to jurisdictional claims in published maps and institutional affiliations. 